\title{
Com quantas palavras se faz um boi
}

Luiz Claudio Vieira de Oliveira*

* Professor Adjunto da Faculdade de Letras da UFMG. 


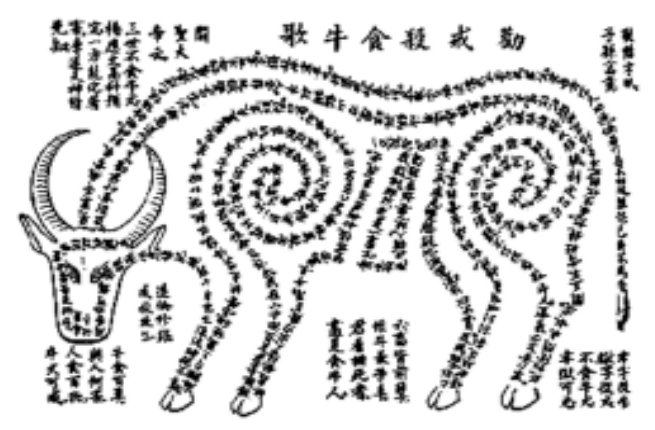

Guimarães R osa é um dos autores da L iteratura B rasileira cujo trabalho com a linguagem ultrapassa o mero uso das palavras para adquirir características metalingüísticas. Foi além do gramaticalmente correto, da erudição ostensiva, procedimento comum a um E uclides da Cunha ou um Coelho Neto, para chegar a uma filosofia e mesmo a uma semiótica da linguagem. Desde Sagarana, num processo sempre crescente, que inclui toda a sua obra, preocupou-se permanentemente com o fazer literário e sua teorização. A crítica literária rosiana, desde sempre, ocupou-se em apontar esta vertente, como se vê nos estudos pioneiros de Oswaldino Marques e M ary Lou Daniel, eminentemente lingüísticos, nos ensaios mais recentes, publicados em A astúcia das palavras, ou nos livros de Heloísa Vilhena de Araújo, J osé Maria Martins, Paulo César C. Lopes e Antônio R oberval Miketen que, por sua vez, abordam o aspecto religioso e as grandes matrizes da literatura e das religiões universais presentes na obra de R osa. J á foram tratados à exaustão o "ileso gume dos vocábulos", a "palavra nunca vista ou jamais ouvida", "a astúcia das palavras" e outras metáforas relativas a essa consciência metalingüística, além da referência constante aos prefácios de Tutaméia, todos eles importantes, pois representam, sob espécie de ficção, uma fundamental teorização sobre a literatura e questões afins. Também os prefácios se tornaram objeto de uma série de estudos, dos quais os mais significativos são os de I rene Gilberto Simões e de Vera Novis.

É nos prefácios e nos contos de Tutaméia, teórica e praticamente, da forma mais escancarada e mais hermética, por paradoxal que pareça, que G uimarães R osa desenvolve a sua vereda metalingüística. Os quatro prefácios discutem as relações dos indivíduos com a língua, a incapacidade criativa e a propensão para a repetição 
que esses têm, a função abdutiva do humor e do não-senso, como elementos desencadeadores da semiose e do novo, o mistério a que se é conduzido pelas palavras. Dentre os contos de Tuta méi a, talvez o mais interessante, como representante dessa reflexão, seja "Os três homens e o boi dos três homens que inventaram um boi", em que o processo de construção do real, ou seja, do referente, se perfaz ante nossos olhos. Tal procedimento tem raízes, dentre outras, no conto "O audaz navegante", de Primeiras estórias, e num dos prefácios, possivelmente o mais divulgado e o menos estudado, que é "Hipotrélico". A estória, referida por G uimarães Rosa, e que dá título ao prefácio, é a que envolve dois personagens: o português e o “indesejável maçante", que contrapõe ao primeiro a inexistência do vocábulo hipotrélico. Ante o argumento de que a palavra não existia, pasma o português: “Como?!... Ora... Pois se eu a estou a dizer?" e, ante a nova negativa, acuado, descobre uma saída e proclama: “- O senhor também é hiputrélico..." F rente à afirmativa peremptória, conclui o narrador: "E ficou havendo". Esta fala do português retoma a referência que R iobaldo faz a Zé B ebelo, em Grande Sertão: Veredas: “... - e êle estava com a raiva tanta, que tudo quanto falava ficava sendo verdade."

Dos episódios, do contexto do prefácio e suas glosas, da interligação mais ampla de todos os prefácios deduz-se que, para uma palavra existir, da mesma forma que uma narrativa, basta que ela seja dita. U mberto E co, analisando a teoria dos códigos, propõe que o referente externo, que diz corresponder ao conteúdo dos signos, ou melhor, ao conteúdo do que caracteriza como sendo uma função sígnica, é o elemento necessário para a elaboração do modelo semiótico, ou do projeto do modelo, apesar de não ser necessário para o seu funcionamento semiótico. No exemplo proposto por U mberto E co, o referente trata-se da água, da represa que a contém e de um código que permite conhecer, à distância, pelo acendimento de lâmpadas em certas seqüências, os estados da água na represa; no caso de Guimarães Rosa, o referente consiste no animal conhecido como representante do gênero Bos Linnaeus. Diz o teórico italiano:

\footnotetext{
U ma vez estabelecido o modelo, e funcionando com base em seus códigos próprios, uma mensagem funcionaria [...] basta que alguém, na fonte, manipulando o aparelho transmissor, decida transmitir uma MENTIRA. O funcionamento semiótico da cadeia toda e as respostas comportamentais do destinatário em nada mudariam. [...] Portanto, toda vez que se manifesta uma possibilidade de mentir, achamo-nos em presença de uma função sígnica. Função sígnica significa possibilidade de significar (e portanto de comunicar) algo a que não corresponde nenhum estado real de fatos ${ }^{1}$.
}

ECO, Umberto. Tratado geral de semiótica. Trad. Antonio de Pádua Danesi, Gilson C. C. de Sousa. São Paulo: Perspectiva, 1980. p. 49 
E ste é o "Abre-te, Sésamo" da criação lexical, da criação ficcional e de toda a literatura. O que o texto literário utiliza é o código, o modelo já pronto e em funcionamento. Os referentes - signos ou funções sígnicas -, sobre que se articula o código, podem ter tido ou não existência concreta, podem tê-la ou não. I sso não é importante, pois não se altera o funcionamento semiótico ou comportamento do destinatário. Ainda que o referente não tenha existência concreta, o texto ficcional não perde sua eficácia. G reimas² já havia abordado essa mesma questão teórica ao criticar a postura dos lingüistas norte-americanos, do neopositivismo anglosaxão, que parte da pressuposição da existência das coisas e de que é preciso darIhes nomes. G reimas, como U mberto E co, considera que são os nomes que criam as coisas, ou seja, que os referentes não precisam, necessariamente, ter existência concreta, como as quimeras. A que estado real de fatos corresponde o boi do conto de Guimarães Rosa? Na verdade, a nenhum. B oi algum é aquele boi que, entretanto, pode ser todos. O que o narrador nos conta é uma mentira.

E m seu texto “A criação do texto literário", L eyla Perrone-M oisés nos diz que o texto nasce de uma dupla falta: a do mundo e a da linguagem. Pela arte, concretizando objetos artísticos, alguns tentam suprir a falta e a insatisfação que sentem do mundo, recriando-o, entre outras formas, pela palavra. Segundo a autora:

Inventar um outro mundo mais pleno ou evidenciar as lacunas desse em que vivemos são duas maneiras de reclamar da falta. Mas aí chegamos ao grande paradoxo que funda o fazer literário. A literatura empreende suprir a falta por meio de um sistema que funciona em falta, em falso: esse sistema é a linguagem. Os signos verbais são substitutos das coisas, seu uso repousa numa mera convenção de correspondência: tal coisa será representada por tal signo. Assim, dizer as coisas é aceitar perdê-las, distanciá-las e até mesmo anulá-las. A linguagem não pode substituir o mundo, nem ao menos representá-lo fielmente. Pode apenas evocá-lo, aludir a ele, através de um pacto que implica a perda do real concreto ${ }^{3}$.

Portanto, frente ao texto literário e, por extensão, a toda a arte, o que se tem é um processo semiótico de representação. Este representar constitui sempre uma distorção, jamais uma adequação. O real que se concretiza em um texto literário já não é mais o real, em estado bruto - que aliás sequer se percebe enquanto tal mas o referente, o real tornado signo e, portanto, "distorcido". E stá-se longe do ideal platônico da mimese e próximo ao pensamento aristotélico, para quem aquela seria a proporcionalidade de formas e não a fidelidade ou equivalência da imagem representada em relação ao real.

GREIMAS, A.J . L'énnonciation. Significação, Araraquara, n. 1, ago. 1974, p. 9-25. ver p. 11.

PERRONE-MOISÉS, Leyla. Flores da escrivaninha; ensaios. São Paulo: Companhia das Letras, 1990. p. 105. 
Ao falar, escrever, pintar ou criar uma música, o homem está considerando a realidade. Mas, de que modo representá-la? Ela não é o que vemos, mas o como vemos. U mberto E co lembra que, na I dade M édia, o rinoceronte era representado segundo determinadas convenções, mesmo que o pintor já conhecesse o animal e soubesse que era totalmente diferente dessa representação pictórica. Portanto, viase uma coisa e representava-se outra, diversa. Quando a fotografia foi inventada, aparentemente exorcizou-se este perigo, essa divergência entre o objeto e sua representação. Segundo Barthes ${ }^{4}$, em "A escrita do visível" e "A retórica da imagem", capítulos de O óbvio e o obtuso, a fotografia é uma imagem sem código. Mas o é apenas no momento em que um aparelho, por um processo físico-químico, capta e registra a parcela de realidade que está à sua frente. Antes e depois deste momento, há um processo de codificação que implica não mais numa representação, mas numa re-presentação. ${ }^{5}$ Normalmente, os usuários de um código, como o lingüístico, não percebem que seu uso implica uma substituição do objeto representado e uma distorção em relação ao mesmo objeto. Peirce irá nos dizer que o signo capta o objeto sob alguns aspectos. Mas, dentro do senso comum, esses usuários crêem que, além de uma correspondência total com o objeto, o signo estabelece uma relação de fidelidade em relação a ele, ou seja, uma relação de verdade. Assim, a adolescente que rasga o retrato do namorado pensa estar causando um mal a ele, uma vez que a foto "é" o namorado; o camponês que evita a palavra demônio acredita que pronunciá-la seja presentificar a entidade demoníaca.

Sabe-se que a representação, a suposta equivalência ou igualdade entre o objeto e seu signo só existe convencionalmente, mesmo que o usuário da língua não o perceba. Ao utilizar o código, ele está, efetivamente, executando uma operação de re-presentação. Onde supõe haver uma correspondência rígida, há um deslizamento constante entre signo e objeto, entre significante e significado, o que permite que os signos se transformem e evoluam. Por outro lado, o uso do código, pela literatura, traduz uma intencionalidade de re-presentação. O autor tem consciência dessa falta, dessa incompletude da linguagem e de outros códigos que possa utilizar. Drummond já percebera o desmedido da tarefa: "Lutar com palavras/ é a luta mais vã/ entanto lutamos/ mal rompe a manhã". A linguagem literária busca e explora a não-correspondência e pretende, intencionalmente, a distorção. Todo discurso literário, assim como os textos produzidos por outros sistemas semióticos, serão um discurso de re-presentação. Pretendê-lo fazer apenas representar significa reduzi-lo ao nível da linguagem comum, cuja característica de re-presentatividade foi esquecida.

\footnotetext{
BARTHES, R oland. O óbvio e o obtuso. Trad. Izabel Pascoal. Lisboa: Edições 70, 1984. passim.

A grafia da palavra representar e cognatos, quando feita com hífen, refere-se ao processo de distorção e diferença na relação entre o signo e o objeto. A grafia comum da palavra considera sua significação usual.
} 
Roland Barthes, nos textos citados, nos diz que, por definição, o conteúdo da fotografia é o real literal e que entre o real e imagem não há um código. Ainda que a imagem não seja o real, mas seu analogon perfeito, é esta perfeição que define a fotografia para o senso comum. A lém da mensagem sem código (analógica) há uma outra mensagem, codificada, correspondente à arte, à escrita, à retórica da foto. Entretanto, todas as vezes que se pretende a objetividade, tenta-se copiar exatamente o real, como se o analógico fosse um fator de resistência ao investimento de valores. A fotografia teria dois planos: o objetivo, denotado, analógico; e o conotado, obtid o pela imposição de um sentido segundo à mensagem fotográfica, por vários processos. O código de conotação é histórico, tanto para a produção da mensagem fotográfica quanto para a sua recepção; são os gestos, atitudes, expressões, cores ou efeitos dotados de certos sentidos um virtude do uso por uma certa sociedade.

Se é assim para a fotografia, também poderá ser, sob certos aspectos, para linguagem. Para esta, a objetividade consistiria numa proximidade do real, como se também para ela o analógico fosse um fator de resistência ao investimento de sentidos. M as, diferentemente da fotografia, a linguagem é, a priori, um código e, portanto, um local de investimento dos gestos, atitudes, expressões dotados de certos sentidos em virtude do uso por uma certa sociedade. Para o código lingüístico, não há o analógico, mas o arbitrário. Para ele, a rigor, não se pode falar de denotação, mas de conotação. O uso do código, na linguagem comum, deve ser considerado como um caso de conotação em primeiro grau; na linguagem literária, como um caso de conotação em segundo grau. Quando o leitor vê certa comunidade entre a obra rosiana e o real, na verdade está buscando um analogon tal qual o que existiria para a fotografia. Se, nesta, o cultural capta o natural, na literatura, o objeto (o real) já foi captado culturalmente pelo código lingüístico (denotativo ou conotativo em primeiro grau) e, ao ser utilizado literariamente, está sendo empregado conotativamente (em segundo grau) pelo mesmo código. O que $B$ arthes ${ }^{6}$ diz quanto à fotografia aplica-se à literatura: "A distinção entre mensagem literal e mensagem conotada é operatória: nunca se encontra uma imagem literal em estado puro. A denotação tem um caráter utópico".

A relação buscada, entre a obra e o real, tem este caráter utópico e, mesmo, mítico. A firmá-la é sublinhar uma equivalência que nunca foi ou será possível e, ao mesmo tempo, erigir uma anterioridade ancestral. Utopia e mito ocorrem no que B arthes chama de o "ter-estado-lá" da fotografia e o "ainda-estar-lá" do mito. Se se aceita como possível ou desejável a correspondência da obra com o real, aceitam-se também estes aspectos utópicos e míticos que transformam a obra num 
discurso ideológico manifestante de uma verdade, ou seja, afeito a e conforme um real preexistente e exterior à obra que poderia ser ainda buscado e encontrado. Na pior das hipóteses, seria possível comprovar que "esteve-lá".

Entretanto, para a literatura, não interessa que o real "tenha-estado-lá" ou que "ainda-esteja-lá". Para ela, tanto faz que este real, este analogon que está representado por suas palavras, tenha existido ou tenha sido inventado, uma vez que, em qualquer dos casos, tornou-se puro referente. Quando o leitor tenta recuperar o analogon, o máximo que consegue é chegar à sua própria maneira de vêlo, à sua própria conotação de primeiro grau. Se M anuelzão correspondia a M anuel $\mathrm{N}$ ardi, morador de Andrequicé, a quem correspondem o velho Camilo ou a J oana Xaviel? Descobrir o analogon de cada um não os torna mais importantes ou mais eficazes ficcionalmente. I sso advém da possibilidade de eles, enquanto personagens, pertencentes a um código, a um sistema semiótico de segundo grau, promoverem a reflexão sobre o sistema de primeiro grau e sobre o real a partir de que são gerados.

Diferente do exemplo de Umberto Eco, em que alguém manipula o transmissor e envia dados errados acerca do estado da barragem, induzindo os habitantes a pensar na iminência de uma enchente e, portanto, enganando-os, o que ocorre na ficção é outra coisa. Qualquer leitor ou espectad or sabe que o texto que tem em mãos é um texto ficcional, cujas marcas ficcionais são evidentes: o título, a perigrafia do texto como um todo, o nome do autor estampado na capa, a presença de um narrador, a inserção do conteúdo do livro num gênero - conto, romance, poesia. O leitor, a tomar o livro, sabe que se trata de uma mentira, de uma ficcionalização. M as alguns leitores, mesmo sabendo-o, procuram no livro marcas de verdade. O que, no meio de todas essas mentiras, dizem eles, é verdade? A paisagem, os personagens, a estória, a época, os costumes e crenças descritos? Não se trataria de verificar as marcas históricas que prendem autor e texto à época em que se manifestaram, mas de buscar a verdade histórica de um texto. Esses leitores perseguem os referentes externos sem perceber que eles, mesmo que existam, não têm existência concreta, ou seja, são meros signos. Ao serem transpostos para a página literária, já não são mais os mesmos. O analogon que o texto literário poderia ter é buscado como garantia de sua autenticidade e verdade, da mesma forma que, segundo $B$ arthes, o aspecto analógico de uma foto funciona como garantia de sua objetividade.

F rente ao texto ficcional, o leitor não pode se esquecer de que se trata, precisamente, de ficção. A o desconhecer este fato, deixa de ser um leitor, ou seja, um fruidor de ficção, para se converter num mero ledor. O texto deve constituir um distanciamento, o local privilegiado a partir do qual o leitor se instala para pensar sobre o real, para ver a si mesmo e ao outro. Ao buscar a verdade contida no texto, 
os seus equivalentes externos, o leitor/ledor converte-se no que U mberto E co chama de leitor empírico que, tal como seu amigo, enxergou no texto situações familiares, acontecimentos sucedidos com seus tios, conhecidos pelo autor e de que ele não tinha o direito de se apropriar. O crítico italiano observa:

O que aconteceu com meu amigo? Ele havia procurado no bosque uma coisa que estava em sua memória particular. [..] Cabe, portanto, observar as regras do jogo, e o leitor-modelo é alguém que está ansioso para jogar. M eu amigo esqueceu as regras e sobrepôs suas próprias expectativas de leitor empírico às expectativas que o autor queria que um leitor-modelo tivesse."

O leitor-modelo é aquele que joga o jogo e não interfere no texto buscando reconhecer situações ou personagens, isto é, particularizando no real algo que já é signo, referente e, portanto, geral.

Nenhum leitor é inocente a ponto de ler um texto ficcional como se fosse um texto, por exemplo, histórico que, sabe-se hoje, não é tão fiel ao real como se pensava. A o tomar um livro, sabe exatamente o que tem em mãos. Quando inicia sua leitura, sabidamente literária, deve compactuar com a narrativa que lhe está sendo contada. Não pode desacreditar daquilo que lê e impor restrições ao narrado. Se o conto "Um môço muito branco" se inicia assim: "Na noite de 11 de novembro de I872, na comarca do Sêrro Frio, em M inas Gerais, deram-se fatos de pavoroso suceder, referidos nas fôlhas da época e exarados nas E femérides", tais fatos só interessam ficcionalmente, mesmo que se comprove sua ocorrência nessa data. Caso contrário, não haverá leitura nem ficção.

Portanto, há duas situações a destacar: deixar-se levar pelos efeitos de real criados pelo texto, acreditando nele e sofrendo as conseqüências dessa crença; ou tentando descobrir no texto as marcas de real que ele contém. No primeiro caso, ao mergulhar na leitura, conforme a metáfora corrente, o leitor submerge totalmente na ficção e a vive intensamente. Além de o texto ficcional propiciar a reflexão sobre si e sobre o outro, cria um efeito de verdade que Ihe provoca várias emoções. M esmo sabendo que tudo aquilo que tem ante os olhos é falso, postiço, fingido, o leitor acredita e se emociona, se empolga, se envolve. Quanto mais profundamente ficcional, maior será esse efeito de verdade e maior será o envolvimento emocional do leitor. No segundo caso, o leitor busca na ficção exatamente o que não é ficcional ou, melhor dizendo, o que não deve ser percebido como ficcional. Não sente o efeito de verdade criado, nem aceita as convenções que o texto impõe exatamente para ser lido como ficção. O primeiro tipo de leitor é o que U mberto 
E co chamou de leitor-modelo; o segundo tipo é o leitor empírico, que procura no texto algo“...que estava em sua memória particular". Quando inseridos num texto, quaisquer fatos, pessoas ou lugares tornam-se ficcionalizados, deixando de pertencer a uma memória particular. E sse processo de ficcionalização não se apóia numa memória, mas num processo de construção de sentidos, aberto a todos que queiram participar.

Haveria, pois, dois instantes na recepção do texto literário: um deles é o que nos faria procurar marcas do real presentes no texto, e não os efeitos de real que o texto cria. Se o autor funciona como aquele que manipula os dados sobre a barragem e sabe que a mensagem que constrói é uma mentira, uma ficção, nem sempre o leitor a recebe assim. Não joga o jogo proposto e prefere buscar o analogon da ficção. O outro instante propiciaria os efeitos de real, capazes de nos emocionar, de nos tocar profundamente, tornando possível a irrupção de todas as 'verdades', constituindo-se naquilo que O. Mannoni chama de "a outra cena":

que está fora [...] do mundo real. É como se no mundo exterior se abrisse um outro espaço, comparável ao palco teatral, ao terreno do jogo, à superfície da obra literária [...] e onde se pode livremente ser sem ser. Liberar-se como palavra pura e fazer de nós ao mesmo tempo o louco que pode dizer tudo e o rei para quem as palavras de seu louco não têm 'conseqüência'. ${ }^{8}$,

É nesta outra cena que se dá o efeito de verdade e onde a ficção reverte sobre o real, fecundando-o: a crença profunda na realidade da fantasia e a certeza de que é apenas fantasia. Esta possibilidade ilimitada de tudo encenar dá ao texto literário e à arte, em geral, a eficácia que têm.

Paradoxalmente, se não fosse dessa forma, a literatura e a arte, de um modo geral, perderiam sua importância. Sua permanência provém desse efeito de real, ou de verdade, que Ihes é atribuído, dessa outra cena onde tudo é possível, inclusive refazer o real. O que é ficcional passa a ser real e, mais ainda, passa a ser verdadeiro por si próprio, pelas relações que cria através da combinação de seus signos. J amais por uma equivalência ao real externo. Não há como não lembrar aqui Fernando Pessoa, com seu poema "Autopsicografia", cuja segunda estrofe exemplifica o efeito de verdade criado pela literatura e que se tentou caracterizar acima: "E os que lêem o que escreve,/ $\mathrm{Na}$ dor lida sentem bem,/ $\mathrm{Não}$ as duas que ele teve,/ Mas só a que eles não têm."9 Esse é o processo que Guimarães Rosa utiliza em seu texto, evidenciando a criação desse efeito de verdade da ficção,

MANNONI, O. Chaves para o imagi nário. Trad. Lígia Vassalo. Petrópolis: Vozes, 1973. p. 99.

PESSOA, Fernando. Obra poética. Rio de J aneiro: Nova Aguilar, 1994. p. 165 
fazendo-o acontecer entre um enunciador - o narrador - e um destinatário externo - o leitor - que reduplicam o que ocorre entre um outro enunciador interno - os vaqueiros - e os vários destinatários internos.

O conto se inicia com uma sugestão, diferente do tom assertivo do "E ra uma vez..." das narrativas tradicionais. Trata-se de: "Ponha-se que estivessem, à barra do campo, de tarde, para descanso." De forma nada afirmativa, pede-se que o leitor suponha. Não há preocupação com o caráter veridictório da estória: é apenas uma suposição. Ao se quebrar o "ovo do silêncio", dá-se início à construção ficcional. $O$ enunciado que temos em mãos parte de um processo de enunciação, cujo sujeito nos propõe um novo processo de enunciação: "Então que, um quebrou o ôvo do silêncio: - Boi..." - certo por ordem da hora citava caso de sua infância, do mundo das inventações; mas o mote se encorpou, raro pela subiteza."(TU, 111) ${ }^{10}$ A partir desse mote, continua o processo coletivo de enunciação e de construção do referente boi, surgido do "mundo das inventações" e depois fingido "[ ...] de graça, no seguir da idéia, nhenganhenga."(TU, 111) A palavra nhenganhenga tem aqui uma dupla significação: por um lado, etimológico, se liga ao tupi, na significação de falar, como nos esclarece Haroldo de Campos, em sua análise do conto lauaretêํ. Por outro lado, é outra maneira de se falar 'lengalenga', dicionarizado como discurso enfad onho e como lenda. Inventado, fingido, gracioso, num dos sentidos apontados no prefácio "A letria e Hermenêutica" para a palavra graça, qual seja, o de dom sobrenatural $(T U, 3)$, feito de nhenganhenga, de pura palavra, pura língua. "Assim o boi se compôs, ant'olhava-os". (TU, 111)

Adiante, o boi é referido como "fiada conversa", "prosa de gabanças e proezas", "peta, patranha, para se rir e rir mais" (TU, 112), mas, ao mesmo tempo, é "vero boi, recente, singular, descrito e desafiado só pelos três". E, num jogo de palavras, cujas origens se acham em Sagarana e Corpo de Baile ${ }^{12}$, o boi balança entre o visto e o ouvido: "Se alguém ouviu o visto, ninguém viu o ouvido [...]" Ou seja, a estória do que tinham visto foi ouvida, mas ninguém viu o que contaram. A partir daí, o Boi ora é confirmado, ora é negado. “Mas o Nhoé se presenciava, certificativo homem, de severossimilhança;" Mas, à frente, lê-se: "O B oi tomava vulto de fato, vice-avêsso", para depois encontrar-se: "Nhoé porém mexeu ombros, repelia o dito. Não achava cautela em dar fiança àquela pública notícia [ ...]"

10 ROSA, J oão Guimarães. Tutaméia. Rio de J aneiro: J osé Olympio, 1969. Todas as referências ao texto ostentarão a abreviatura do livro e a página citada, entre parênteses.

11 CAMPOS, Haroldo de. Metalinguagem. São Paulo: Cultrix, 1976. A linguagem do iauaretê, p. 47-53. Ver p. 49.

12 "E eu que vinha vivendo o visto, mas vivando estrelas" (Sagarana) e "O cozinheiro-de-boiada Massacongo: Do justo o certo, do certo o crido, do crido o havido: que êle veio mas foi com tropa bôa, esquipada, de bêstas e burros, e o jumento; ouvi. E assim que: o Peralta contou à Iàs-F lôres, Iàs-F lôres contou a M aria Fé, M aria Fé contou à Colomira, aí Colomira me disse. Daí é que sei... Vou indo!" 
A mulher do J erevo "[...] instruía-os de estróinas novidades: que, por aí, reinava uma guerra, drede iam remeter para lá a mocidade, o mar, em navio." Ante o B oi, a notícia da guerra soava como falsidade: “[ ...] ainda bem que o escrúpulo da gente regra as quentes falsidades." Por sua vez, a mulher do J erevo ria deles, do boi desenhado: “ - 'Sai, boi!' - ela troçava mistério deles, do que fino se bosquejava. 0 B oi bôbo - de estatura." E agora é a vez de J elázio descrer do Boi "[ ...] arrenegar essa lembrança".

Ante as lembranças dos amigos, que recordavam "mães e meninices e terras", reais ou construídas, como o Boi, N hoé filosofa: "No de-dentro, as criaturas tôdas eram igualadas; no de-fora, só por não perceberem uns dos outros o escondido é que venciam conviver com afetos de concórdia." Ou seja, a convivência entre pessoas se faz também com referentes e não com "estados reais de fatos". Por isso o medo de $\mathrm{N}$ hoé quando, ao imaginarem o boi, ele "quis que se fôssem dali - por susto do real, ciente de que com a mulher do J erevo J elázio vadiava": referentes e estados reais de fatos podiam se misturar, confundindo-se. Com o passar do tempo, a mulher do J erevo morre e, ao voltarem do enterro, relembram o Boi, a ocasião "aprazível tão quieta, reperfeita, em beira de um campo, quando a informação do Boi tinha sobrevindo, de nada, na mais rasa conversa, de felicidades." E o B oi torna-se apenas lembrança, passado, em que não se mexe. "Daí, mencionavam mais nunca o referido urdido - como não se remexe em restos".

Tempos depois, morto o J elázio, J erevo resolve partir. Nhoé fica só e, velho e pobre, resolve voltar para sua terra. "Achou de bom ir embora. Voltava para conturva distância, pedind o perdão aos lugares." N o caminho, chega a uma fazenda, achega-se aos vaqueiros, assenta-se ao pé do fogo, cochila. Os vaqueiros contavam casos. De repente:

\footnotetext{
Refalavam de um boi, instantâneo. Listrado riscado, babante, façanhiceiro! que em várzeas e glória se alçara, mal tantas malasartimanhas - havia tempos fôra, Nhoé disse nada. O que nascido de chifres dourados ou transparentes, redondo o berro, a côr de cavalo. Ninguém podia com êle - o Boi Mongoavo. Só três propostos vaqueiros o tinham em fim sumetido...
}

O boi agora era o Boi. O que ficou havendo. O boi de palavras, surgido, à barra do campo, de tarde. Nascido do nada, cresceu, desenvolveu-se, caracterizou-se: façanhiceiro. Um boi semiótico, pode-se dizer. Feito apenas de signos, criado por inventações, o boi passa a existir. O que era uma função sígnica passa a real, ou melhor, passa a verdade. O boi passa a ter nome: era o B oi Mongoavo. $\mathrm{O}$ processo de criação, de ficcionalização, se completou. O que era mentira veio a ser verdade. Dizer o boi correspondeu a fazê-lo. 
